\title{
Objective relief of vasospasm by glyceryl trinitrate in secondary Raynaud's phenomenon
}

\author{
J.S. Coppock ${ }^{1}$, J.M. Hardman ${ }^{2}$, P.A. Bacon ${ }^{1}$, K.L. Woods ${ }^{3}$ and M.J. Kendall ${ }^{3}$ \\ Departments of ${ }^{1}$ Rheumatology, ${ }^{2}$ Surgery and ${ }^{3}$ Therapeutics, University of Birmingham, Birmingham, UK.
}

\begin{abstract}
Summary: An objective response to topical glyceryl trinitrate was shown by digital plethysmography in a study of 17 patients with Raynaud's phenomenon. Improvement was significant $(P<0.005)$ in those in whom the disease was secondary to an underlying connective tissue disorder. The response suggests that the effect of this drug is mediated locally.
\end{abstract}

\section{Introduction}

Raynaud's phenomenon is a common condition; recent estimates of its prevalence are as high as $5-10 \%$ of the population (Olsen \& Nielson, 1978). It may occur in isolation (primary) or in association with connective tissue diseases such as systemic sclerosis and systemic lupus erythematosus (SLE) (secondary). In its most severe form, digital ulceration and gangrene may result.

Assessment of treatment for Raynaud's phenomenon has been hampered by natural fluctuations in the severity of symptoms, widespread reliance on subjective indices of therapeutic response and difficulties with classification. Despite trials of a wide range of vasoactive drugs, treatment remains unsatisfactory. In one study of patients with secondary Raynaud's phenomenon (Franks, 1982), subjective clinical assessment suggested topical glyceryl trinitrate (GTN) was a useful adjunct to sympatholytic drugs.

We have investigated the activity of GTN alone in both primary and secondary Raynaud's phenomenon using a single objective endpoint measure to determine outcome.

\section{Patients and methods}

We undertook a randomized, double-blind, placebocontrolled study in 17 patients with Raynaud's phenomenon using a protocol submitted to and approved by the Central Birmingham Health District Research Ethical Committee. The patients were recruited from hospital outpatient clinics and each gave their consent

Correspondence: J.S. Coppock, M.B., B.Sc., M.R.C.P., Whipps Cross Hospital, Leytonstone, London E11 9NR, UK

Accepted: 31 July 1985 to participate after the nature and purpose of the trial had been explained.

Ten patients had secondary Raynaud's phenomenon and were classified according to the criteria of the American Rheumatism Association for SLE (Tan et al., 1982) or scleroderma (Subcommittee for Scleroderma Criteria of the ARA, 1980). The associated connective tissue disease was scleroderma in 5 and SLE in 4, one patient had a scleroderma overlap syndrome. The primary or idiopathic group were defined by the presence of symmetrical Raynaud's phenomenon, the absence of clinical evidence of connective tissue disease or gangrene, and a disease duration of greater than 5 years.

Response was assessed using the Nielsen apparatus (Nielsen \& Lassen, 1977; Nielsen, 1978). On arrival at clinic, patients were first rested for 30 minutes and then moved to a temperature controlled room $\left(20^{\circ} \mathrm{C}\right)$ in which all measurements of finger systolic pressure (FSP) were undertaken. For each assessment of FSP a water filled cuff was placed in fixed position over the middle finger. This was perfused by water at controlled temperature and pressure using the mediamatic apparatus. Distal to the cuff was a mercury in silastic plethysmograph sensitive to pulsation in the digital pulp. For these studies the pulp was emptied and the cuff inflated to $200 \mathrm{mmHg}$ pressure at a temperature of $30^{\circ} \mathrm{C}$ or $15^{\circ} \mathrm{C}$ for $5 \mathrm{~min}$. The cuff was then deflated at a controlled rate of $2 \mathrm{mmHg} / \mathrm{s}$ until the point was reached when the digital pulp refilled. This end point was taken as the finger systolic pressure. The coefficient of variation for repeated measurements on the same patient at different times with this method was $14 \%$. Using this technique a fall in FSP has been demonstrated in patients with Raynaud's phenomenon after local cooling to $15^{\circ} \mathrm{C}$, in excess of that seen in healthy volunteers. We believe that this fall in 
FSP is an assessment of local vasospasm induced by cold.

For each patient FSP was measured after the digit was exposed to two different cuff temperatures. Measurements were taken in triplicate, first at $30^{\circ} \mathrm{C}$ and then at $15^{\circ} \mathrm{C}$ for each patient before and after treatment with active and placebo ointment. After the initial measurements of FSP had been taken, by random assignment each patient had one hand treated with $5 \mathrm{~g}$ of $1 \%$ GTN in white soft paraffin and the other hand with white soft paraffin alone. The ointment was applied by a single observer (who was blind to treatment) over the hand from the mid palmar crease to the finger tips. After a fixed time of one and a half hours, measurement of FSP at $30^{\circ} \mathrm{C}$ and then $15^{\circ} \mathrm{C}$ was repeated (in triplicate), the observer being blind to treatment. Average values of the triplicate measurements were used for subsequent calculations.

For each hand the FSP (at each temperature studied) before treatment was subtracted from the FSP (at the same temperature) after treatment. In each patient we calculated the change in FSP for both the placebo treated hand and the actively treated hand. The difference between these (change due to active treatment - change due to placebo treatment) is the treatment effect, i.e. the effect attributable to GTN.

Non-parametric statistical analysis was performed using the Mann Whitney test.

\section{Results}

The condition was symmetrical in individual patients, thus initial finger systolic pressures at $30^{\circ} \mathrm{C}$ or $15^{\circ} \mathrm{C}$ were not significantly different between active and placebo treated hands. Patients with primary or secondary Raynaud's phenomenon did not diffor significantly in their initial (pre-treatment) FSPs and were similar in terms of age (primary, median 39 years. range 19-74: secondary, 52 years, range 24-737, disease duration (primary, 9.5 years, range 5-10: secondary, 8 years, range $0.5-20$ ) and disease severity, which was assessed subjectively by a $10 \mathrm{~cm}$ horizon visual analogue scale (primary, $65 \mathrm{~mm}$, range 11secondary, $59 \mathrm{~mm}$, range 3-95).

We could demonstrate no significant changes in FSP following treatment in the actively or placeb8 treated hands alone (see Table I) in any patient grou $\vec{p}$. The secondary group showed a trend towards ing provement in the actively treated hand alone at $30 \mathbb{\&}$ and $15^{\circ} \mathrm{C}$ but numbers were too small to attain statistical significance.

The treatment effect did not demonstrate any difference with treatment in the FSP measured $30^{\circ} \mathrm{C}$. However, after cold stress at $15^{\circ} \mathrm{C}$, a significant increase in FSP was evident in the whole group $(P<0.02)$. This derived from those patients with secondary Raynaud's phenomenon (see Figure 1) $\overrightarrow{\mathrm{d} n}$ which GTN treatment significantly increased FSP ${ }_{0} \mathrm{t}$ $15^{\circ} \mathrm{C}(P<0.005$, point estimate of drug effect $45 \mathrm{mw}$, $95 \%$ confidence interval 9 to $63 \mathrm{~mm}$ ). All but ofe showed a positive effect of GTN, the non-resposider was a patient with a severe scleroderma ovel 10 syndrome and partial finger loss. She had no dewom strable finger blood flow.

In contrast the primary group response was vario ble, one patient exhibiting a good response to GTH, though there was no overall change in FSP (point

Table 1 Changes in FSP ( $\mathrm{mmHg}$ ) after treatment for the active and placebo treated hands for the two cuff temperatures studied $\left(30^{\circ} \mathrm{C}\right.$ and $\left.15^{\circ} \mathrm{C}\right)$. These were calculated for each patient as the difference between pre-treatment and post-treatment FSP. The treatment effect is the difference between the change in FSP in the actively treated hand and the change in FSP in the placebo treated hand.

\begin{tabular}{|c|c|c|c|c|c|c|}
\hline & \multicolumn{2}{|c|}{$\begin{array}{l}\text { Change in FSP for } \\
\text { actively treated hands } \\
\text { Cuff temperature }\end{array}$} & \multicolumn{2}{|c|}{$\begin{array}{l}\text { Change in FSP for } \\
\text { Placebo treated hands } \\
\text { Cuff temperature }\end{array}$} & \multicolumn{2}{|c|}{$\begin{array}{l}\text { Treatment effect } \\
\text { Cuff temperature }\end{array}$} \\
\hline & $30^{\circ} \mathrm{C}$ & $15^{\circ} \mathrm{C}$ & $30^{\circ} \mathrm{C}$ & $15^{\circ} \mathrm{C}$ & $30^{\circ} \mathrm{C}$ & $15^{\circ} \mathrm{C}$ \\
\hline $\begin{array}{l}\text { All patients } \\
n=17\end{array}$ & $24(-22$ to 71$)$ & $16(-22$ to 57$)$ & $12(-74$ to 52$)$ & $0(-63$ to 56$)$ & $5(-48$ to 121$)$ & $20 *(-56$ to 122 \\
\hline $\begin{array}{l}\text { Primary } \\
\text { Raynaud's } \\
\text { phenomenon } \\
n=7\end{array}$ & $24(-22$ to 71$)$ & $0(-22$ to 57$)$ & $16(-35$ to 40$)$ & $0(-32$ to 56$)$ & $4(-19$ to 55$)$ & $0(-56$ to 71$)$ \\
\hline $\begin{array}{l}\text { Secondary } \\
\text { Raynaud's } \\
\text { phenomenon } \\
n=10\end{array}$ & $22.5(-13$ to 58$)$ & $31.5(0$ to 59$)$ & $4.5(-75$ to 40$)$ & $-3.5(-63$ to 22$)$ & $7.5(-48$ to 121$)$ & $44^{* *}(0$ to 122$)$ \\
\hline
\end{tabular}

The median value and range (in parentheses) are shown for all patients, and those with primary or secondary Raynaud?s phenomenon at the two different cuff temperatures. ${ }^{*} P<0.02,{ }^{* *} P<0.005$ (Mann Whitney). 


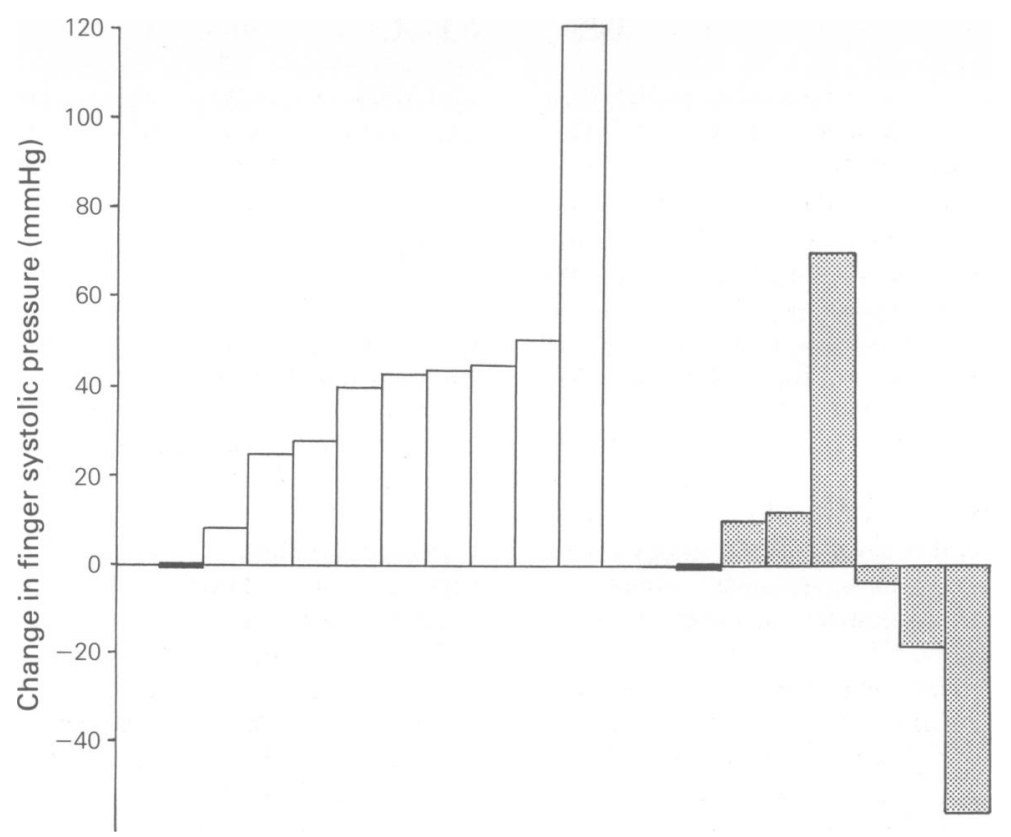

Figure 1 Treatment effect for individual patients - cuff temperature $15^{\circ} \mathrm{C}$. (网) primary; ( $\square$ ) secondary.

estimate $0 \mathrm{~mm}, 95 \%$ confidence interval -45 to $39 \mathrm{~mm}$ ).

No relationship was seen between immunological abnormalities and change in FSP. None of the patients with primary Raynaud's phenomenon had soluble nuclear antigens, though 2 had weakly positive antinuclear antibodies on Hep-2 cells.

Four patients experienced headache, which we attribute to systemic absorption of GTN. In 3 of these patients the headache commenced over 2 hours after the drug was removed. No other adverse effects occurred.

\section{Discussion}

An earlier report (Franks, 1982) suggested topical GTN may be effective in combination with oral vasodilators. The present study, using objective assessments, shows that it can reduce cold-induced vasospasm when used alone in secondary Raynaud's phenomenon. We could demonstrate no such effect in primary Raynaud's phenomenon, though the pattern of response in this group is of interest as it has been shown (Gerbracht et al., 1985; Porter et al., 1976) that on long term follow-up a proportion of these patients develop connective tissue disease. Whilst two patients with primary Raynaud's phenomenon had weakly positive antinuclear antibodies on Hep-2 cells in the absence of diagnosable connective tissue disease, we could determine no relationship between the occurrence of autoantibodies and response to GTN. The reason for the difference in response of the primary and secondary group is unclear. A recent study of the calcium antagonist, diltiazem, produced exactly the opposite effect (Kahan et al., 1985). Diltiazem appeared to improve those with primary but not those with secondary Raynaud's phenomenon.

Horhota \& Fung (1979) have shown that GTN ointment applied to the abdominal skin surface of rats results in elevated serum levels for at least 4 hours and that $60 \%$ of the applied GTN is recoverable from skin surface sections after that time. In a study on human subjects with congestive cardiac failure, Armstrong and colleagues (1980) have shown that despite its short half life of 1.9 minutes GTN is still detectable in the serum of patients half an hour after the ointment was removed from the skin by scraping and washing in alcohol. They have suggested that there may be a local depot in the skin for GTN. The late development of headaches in our patients would add further support to this hypothesis. The mechanism of action of GTN remains unclear even in angina pectoris where it has been extensively studied (Editorial, 1984). There is evidence for a dose related effect on coronary vessels of different sizes (Feldman et al., 1982).

Imhof et al. (1980) have suggested that high doses of GTN produce progressive reductions in peripheral arterial resistance. The asymmetry of response with this agent in our patients suggests that its action is 
predominantly local perhaps reflecting a high concentration of GTN in the digital tissues. The need for high tissue concentrations could also explain the lack of effectiveness of systemic GTN (Sovijarvi et al., 1984) in Raynaud's phenomenon.

The long term efficacy of GTN remains to be shown but it clearly has an effect on finger systolic pressure, though the pharmacokinetics of this action require further study. Whether this effect improves nutritional blood flow is unclear but its simplicity and lack of serious side effects makes it a candidate for long-term

\section{References}

ARMSTRONG, P.W., ARMSTRONG, J.A. \& MARKS, G.S. (1980). Pharmacokinetic-haemodynamic studies of nitoglycerin ointment in congestive heart failure. American Journal of Cardiology, 46, 670.

EDITORIAL (1984). Nitrates and angina; Lancet, i, 998.

FELDMAN, R., MARX, J.D., PEPINE, C.J. \& CONTI, C.R. (1982). Analysis of coronary responses to various doses of intracoronary nitroglycerin. Circulation, 66, 321.

FRANKS, A.G. (1982). Topical GTN as adjunctive treatment in Raynaud's disease. Lancet, $\mathbf{i}, 76$.

GERBRACHT, D.D., STEEN, V.D., ZIEGLER, G.L., MEDSGER, T.A. \& RODNAN, G.P. (1985). Evolution of primary Raynaud's phenomenon (Raynaud's disease) to connective tissue disease. Arthritis and Rheumatism, 28, 87.

HORHOTA, S.T. \& FUNG, H.L. (1979). Percutaneous nitroglycerin absorption in rats. Journal of Pharmaceutical Sciences, 68, 608.

IMHOF, P.R., OTT, B., FRANKHAUSER, P., CHU, L.C. \& HODLER, J. (1980). Difference in nitroglycerin dose response in the venous and arterial beds. European Journal of Clinical Pharmacology, 18, 455.

KAHAN, A., AMOR, B. \& MENKES, C.J. (1985). A randomised double blind trial of diltiazem in the treatment of Raynaud's phenomenon. Annals of the Rheumatic Diseases, 44, 30.

NIELSEN, S.L. (1978). Raynaud's phenomenon and finger systolic pressure during cooling. Scandinavian Journal of studies. It appears that topical GTN offers an accept ble, safe therapy for Raynaud's phenomenon and are currently assessing long-term efficacy with this ar other methods of drug delivery.

\section{Acknowledgements}

Mr S.R. Potter, Principal Pharmacist, Queen Elizabef Hospital for the preparations for GTN and placebo. JSC isa Sheldon Clinical Research Fellow.

Clinical and Laboratory Investigation, 38, 765.

NIELSEN, S.L. \& LASSEN, N.A. (1977). Measurement בైf digital blood pressure after local cooling. Journal कुष Applied Physiology, 43, 907.

OLSEN, N. \& NIELSEN, S.L. (1978). Prevalence of primañ Raynaud phenomenon in young females. Scandinavian Journal of Clinical and Laboratory Investigation, 37, 769? PORTER, J.M., BARDANA, E.J., BAUR, G.M., WESCHE, D.P. RUEDIGER, H., ANDRASH, R.H. \& ROSCH, J. (1976). The clinical significance of Raynaud's syndrome. Surgery, $\$$ 756.

SOVIJARVI, A.R., SIITONEN, L. \& ANDERSSON, P. (198 Transdermal nitroglycerin in the treatment of Raynauts phenomenon: analysis of digital blood pressure chigige after cold provocation. Current Therapeutic Researct 832.

SUBCOMMITTEE FOR SCLERODERMA CRITERIA OF于 AMERICAN RHEUMATISM ASSOCIATION DIAGNOSTEC AND THERAPEUTIC CRITERIA COMMITTEE. (198\%. Preliminary criteria for the classification of systenfic sclerosis (scleroderma). Arthritis and Rheumatism, 23, $58 \mathrm{~g}$

TAN, E.M., COHEN, A.S., FRIES, J.F., MASI, A.T., MCSHANE D.J., ROTHFIELD, N.F., SCHALLER, J.G., TALAL, N. WINCHESTER, R.J. (1982). The 1982 revised criteria for the classification of systemic lupus erythematosus. Arthri and Rheumatism, 25, 1271. 